\title{
Lamiaceae Peppermint Oil with Surfactant Showing Equal Antifungal Activity against Candida albicans to Rosemary Chemotype
} CINEOL

\author{
Yusuke Matsuzaki', Yasuaki Kakinoki', Mari Nakamura1, Tatsuji Nishihara ${ }^{2}$, \\ Toshiyuki Tsujisawa ${ }^{3 *}$ \\ ${ }^{1}$ Division of Special Needs and Geriatric Dentistry, Department of Physical Functions, \\ Kyushu Dental University, Kitakyushu, Japan \\ ${ }^{2}$ Division of Infections and Molecular Biology, Department of Health Promotion, \\ Science of Health Improvement, Kyushu Dental University, Kitakyushu, Japan \\ ${ }^{3}$ Department of Oral Health Management, School of Oral Health Sciences, \\ Kyushu Dental University, Kitakyushu, Japan \\ Email: matsu.44.yum.44@gmail.com, ${ }^{*}$ t-toshi@kyu-dent.ac.jp
}

Received 21 January 2014; revised 21 February 2014; accepted 28 February 2014

Copyright (C) 2014 by authors and Scientific Research Publishing Inc.

This work is licensed under the Creative Commons Attribution International License (CC BY). http://creativecommons.org/licenses/by/4.0/

(c) (i) Open Access

\begin{abstract}
Oral candidiasis causes pain in oral cavity or tongue. Antifungal drugs are commonly used for the treatment of candidiasis, however, there could be several problems such as side effects, drug resistance, or contraindication to concomitant use with drugs already taken. The development of substituting antimicrobial agents, which could be used internally or as gargling agents, is expected. Some essential oils have been known for the activities against microbes. We focused on the three chemotype essential oils from rosemary and five essential oils from Lamiaceae plants including rosemary, and examined their antifungal activity against Candida albicans by broth microdilution method. The activity with or without addition of Tween 80 or Tween 20 was statistically analyzed. Minimal inhibitory concentration (MIC) values of the essential oils were significantly decreased when either of the two surfactants was added. Among the tested oils, only CAMPHOR, a rosemary chemotype, showed a significantly lower MIC with addition of Tween 20 than Tween 80 . It is inferred that the antifungal activity of essential oils is influenced by the type of surfactants. Some of the essential oils showed the same values of MIC and the minimal fungicidal concentration (MFC) when surfactant was added. Peppermint showed the same MICs and MFCs in most cases, and its low MFC indicated potent fungicidal activity against $C$. albicans, as observed in CINEOL. We will
\end{abstract}

${ }^{*}$ Corresponding author.

How to cite this paper: Matsuzaki, Y., Kakinoki, Y., Nakamura, M., Nishihara, T. and Tsujisawa, T. (2014) Lamiaceae Peppermint Oil with Surfactant Showing Equal Antifungal Activity against Candida albicans to Rosemary Chemotype CINEOL. Advances in Infectious Diseases, 4, 58-65. http://dx.doi.org/10.4236/aid.2014.41010 
discuss peppermint oil as one of the potential candidates for antifungal agents against $C$. albicans.

\title{
Keywords
}

\author{
Essential Oil; Rosemary; Peppermint; Chemotype; Surfactant; Candida albicans
}

\section{Introduction}

Candida albicans is widely present in oral cavity, gastrointestinal tract and vagina as a human microbial flora and causes various opportunistic diseases in its compromised hosts. Oral and oesophageal candidiases cause pain in oral cavity and tongue, taste disturbances, odynophagia or dysphagia. Antifungals are generally used for the treatment, however, there could be several problems such as side effects, drug resistance, and contraindication to concomitant use with drugs already taken. The development of alternative agents to decrease these problems is expected.

It is known that extracts from some medicinal and aromatic plants have antimicrobial activities [1]. Essential oils are natural materials extracted from flowers, leaves, buds, twigs, roots, seeds, or woods of aromatic plants [2]. Each essential oil has peculiar effects, and there have been studies to examine its antimicrobial property for the use in alternative medicine or food preservation [3].

In our previous study on the antifungal activity against $C$. albicans of seven essential oils, an addition of a non-ionic surfactant, Tween 80, potentiated the activity several times [4]. It would be worth examining essential oils as one of possible substitutes for antifungal agents.

Some plants produce essential oil chemotypes, which are derived from the same plant species but have different chemical components. There have been some reports on the effects of rosemary oil against C. albicans, but none of them had gone into the specifics on the chemotypes. The results from these studies are inconsistent [5]-[7]. It could be inferred that this inconsistency is due to the variation of chemical components of chemotypes. In this study, we aim to examine the stability of the antifungal activity of these essential oils and to compare the influence of surfactants on the activity.

Among non-ionic surfactants used as solubilizing agents at low concentration, we focused on two surfactants, Tween 80 and Tween 20, which were most commonly used in the biotechnology industry [8] [9]. We compared each antifungal activity of essential oils with addition of Tween 80 or Tween 20, and statistically analyzed the data. We also examined whether other Lamiaceae essential oils show significant antifungal activity as CINEOL.

\section{Materials and Methods}

\subsection{Essential Oils and Other Reagents}

The three chemotype essential oils of rosemary, CINEOL, VERBENON and CAMPHOR, were obtained from LIBRA NATUTHERAPY, Hyogo, Japan. The five essential oils from Lamiaceae plants, rosemary (Rosmarinus officinalis), peppermint (Mentha piperita), lavender (Lavandula angustifolia), sweet marjoram (Origanum majorana), and clary sage (Salvia sclarea), were obtained from two manufacturers; LIBRA NATUTHERAPY, Hyogo, Japan and Flavor Life, Tokyo, Japan. These five Lamiaceae oils are popular and readily obtained in Japan. Some Lamiaceae plants produce chemotypes, however, except for rosemary, the chemotype oils of the other Lamiaceae plants were not available in Japan.

The parts (leaves) and methods for extraction (steam distillation) of the three rosemary chemotypes were the same, while the habitats were different (Morocco, France, and Spain) [4]. The five Lamiaceae oils were also obtained through steam distillation methods. The extraction parts of lavender and clary sage were leaves and flowers, while other three oils were from leaves. Except for lavender (France) and Sweet marjoram (Egypt), the habitats of the other three oils differed between manufactures A and B (Table 1).

The three rosemary chemotypes and five Lamiaceae oils at various concentrations were dissolved in RPMI 1640 with L-glutamine and 0.165 M MOPS, without sodium bicarbonate (MOPS buffered RPMI 1640) (Lonza, Allendale NJ, USA). Polyoxethylene (20) Sorbitan Monooleate (Tween 80) and Polyoxyethylene (20) Sorbitan Monolaurate (Tween 20), as emulsifiers, were purchased from Wako Pure Chemical Industries, Osaka, Japan. 
Table 1. The five Lamiaceae essential oils profile.

\begin{tabular}{|c|c|c|c|c|c|}
\hline \multicolumn{2}{|c|}{ Aromatic plants } & \multirow{2}{*}{ Extracted part } & \multirow{2}{*}{$\begin{array}{c}\text { Extracting } \\
\text { method }\end{array}$} & \multicolumn{2}{|c|}{ Habitat } \\
\hline Common name & Scientific name & & & Manufacture A & Manufacture B \\
\hline Rosemary & Rosmarinus officinalis & Leaves & steam distillation & Spain & Morocco \\
\hline Peppermint & Mentha piperita & Leaves & steam distillation & India & United States \\
\hline Lavender & Lavandula angustifolia & $\begin{array}{l}\text { Leaves and } \\
\text { Flowers }\end{array}$ & steam distillation & France & France \\
\hline $\begin{array}{c}\text { Sweet } \\
\text { marjoram }\end{array}$ & Origanum majorana & Leaves & steam distillation & Egypt & Egypt \\
\hline Clary sage & Salvia sclarea & $\begin{array}{l}\text { Leaves and } \\
\text { Flowers }\end{array}$ & steam distillation & France & Bulgaria \\
\hline
\end{tabular}

\subsection{Fungal Strains and Culture Conditions}

C. albicans ATCC 18804 was maintained in YEAST MOLD BROTH (YM broth) (Becton, Dickinson, Franklin Lakes, NJ, USA) at $28^{\circ} \mathrm{C}$ for 48 hours. The yeast colonies were adjusted to approximately $5-6 \times 10^{5} \mathrm{CFU} / \mathrm{ml}$ before inoculation.

\subsection{MIC and MFC Assays against C. albicans}

The MIC was measured by two-fold serial broth dilution assay, based on the Clinical and Laboratory Standards Institute (CLSI) reference protocol M27-A3 with modification. The experiments were performed using sterile 96well plates. C. albicans suspended in MOPS buffered RPMI 1640 and adjusted to $1-5 \times 10^{3} \mathrm{CFU} / \mathrm{ml}$ were added to each well. The plates were cultured at $35^{\circ} \mathrm{C}$ for 48 hours and the MICs were determined. The MIC was defined as the lowest concentration to prevent visible growth of $C$. albicans. The concentration range of the Lamiaceae essential oils and rosemary chemotypes was $0.02-20 \mu \mathrm{l} / \mathrm{ml}$.

To determine the minimal fungicidal concentration (MFC), the fluids from all wells showing an inhibition of the fungal proliferation in MIC assay were subcultured in $10 \mathrm{ml}$ of YM broth at $28^{\circ} \mathrm{C}$ for 48 hours. The MFC was defined as the lowest concentration to completely prevent the development of the inoculums.

To standardize the assay, we confirmed the MIC of amphotericin B against C. albicans $0.25-1.0 \mu \mathrm{g} / \mathrm{ml}$. An essential oil-free, control medium was inoculated with C. albicans, and the growth was observed. It was found that $0-20 \mu \mathrm{l} / \mathrm{ml}$ Tween 80 and Tween 20 did not affect the fungal growth. All experiments were performed in at least triplicate.

\subsection{Statistical Analyses}

Data on the three chemotypes were displayed in box-and-whisker plots. In order to measure the antifungal activity of essential oils against $C$. albicans, Mann-Whitney $U$ test with Bonferroni correction was employed for the comparison of the MICs with and without surfactants. $P$-values $<0.0166$ were considered significant. For the difference between manufacturers A and B, the data were analyzed without Bonferroni correction ( $P$ $<0.05$ ). Statistical analyses were performed using SPSS (Statistical Package for the Social Science) Ver. 21.

\section{Results}

\subsection{Antifungal Activity of Rosemary Chemotypes against $C$. albicans}

The antifungal activity of the three rosemary chemotypes was examined using Mann-Whitney U test. It was found that the MICs with either Tween 80 or Tween 20 were significantly lower than those without surfactants. When the surfactants added, the MICs almost coincided with the MFCs (Table 2). Among the three chemotypes, only CAMPHOR showed significantly lower MIC with Tween 20 than with Tween 80 (Figure 1).

\subsection{Antifungal Activity of the Lamiaceae Oils against $C$. albicans}

In the five Lamiaceae oils, MICs with either Tween 80 or Tween 20 also fell significantly (Tables 3 and 4). There were no significant differences between the effects of the two surfactants on the MICs. However, comparing 
Table 2. The MICs and MFCs of rosemary chemotypes against C. albicans.

\begin{tabular}{ccccccc}
\hline \multirow{2}{*}{ Chemotype } & \multicolumn{2}{c}{ without surfactant } & \multicolumn{2}{c}{ with Tween 80} & \multicolumn{2}{c}{ with Tween 20} \\
\cline { 2 - 7 } & MIC & MFC & MIC & MFC & MIC & MFC \\
\hline CINEOL & $5.0-20.0$ & 20.0 & $1.25-2.5$ & $1.25-2.5$ & $1.25-2.5$ & $1.25-2.5$ \\
VERBENONE & $10.0-20.0$ & 20.0 & $2.5-5.0$ & $2.5-5.0$ & $2.5-5.0$ & $2.5-5.0$ \\
CAMPHOR & $10.0-20.0$ & 20.0 & $5.0-10.0^{*}$ & $5.0-10.0$ & $2.5-5.0^{*}$ & $2.5-5.0$ \\
\hline
\end{tabular}

The numerical values are indicated in $\mu \mathrm{l} / \mathrm{ml}$. The addition of Tween 80 or Tween 20 affected MICs significantly. ${ }^{*} P<0.0166$ vs Tween 80 and Tween 20.
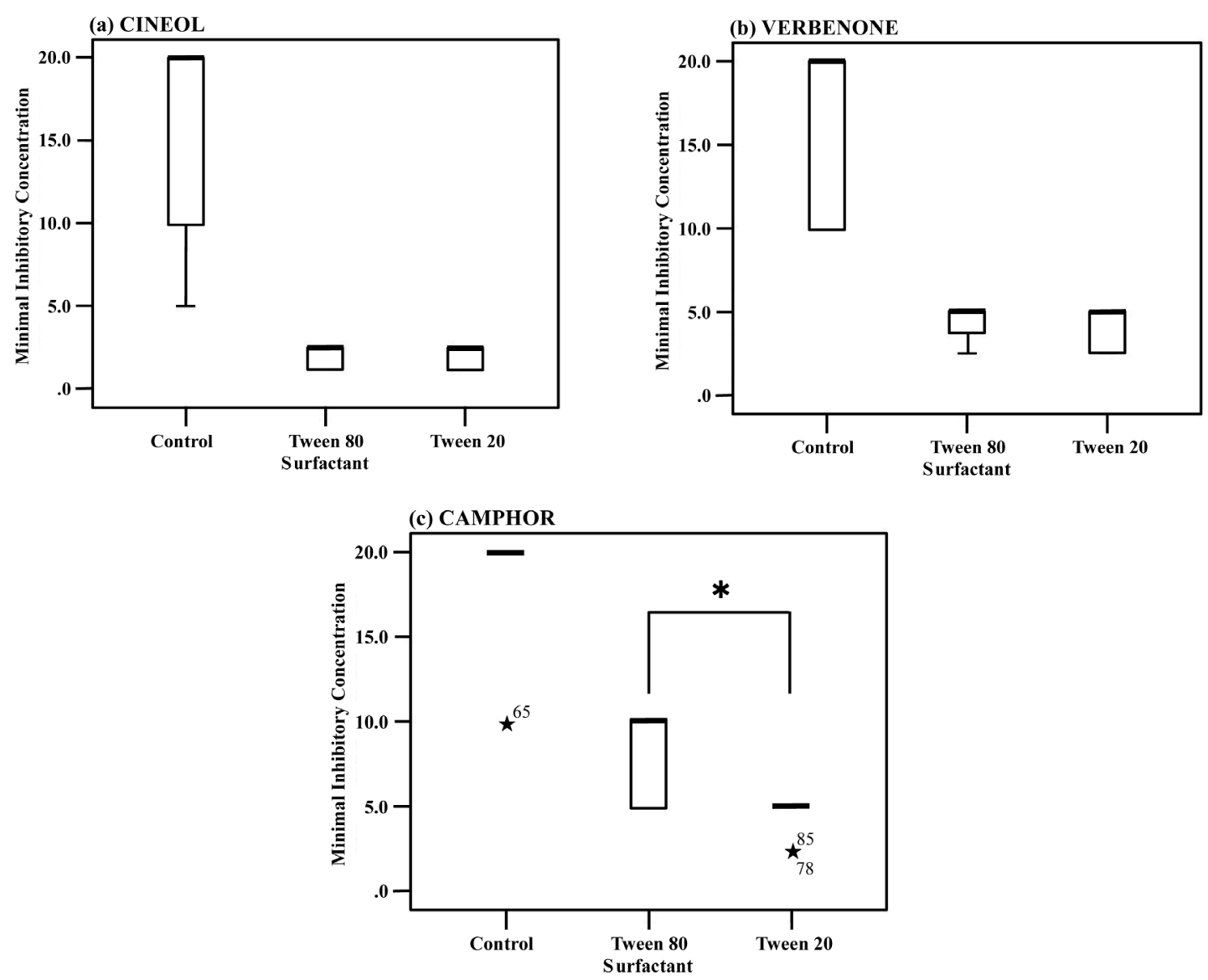

The length of the box is the interquartile range based on Tukey's hinges, and the median is identified by a heavy line. The numerical values in the figures are data more than 1.5 times the interquartile range, and the numbers stand for case numbers. The values more than tripled are defined as extreme values and denoted with $\star$. Among the three rosemary chemotypes except for CAMPHOR, no significant difference observed in MICs between Tween 80 and Tween $20 .{ }^{*} P<0.0166$ vs Tween 80 and Tween 20 . Box-and-whisker plots showing the antifungal activities of rosemary chemotypes against $C$. albicans with addition of Tween 80 or Tween 20 compared to the inoculated control (without surfactant).

Figure 1. The antifungal activity of CINEOL (a), VERBENONE (b), CAMPHOR (c).

the minimum MICs with Tween 20 to those with Tween 80, rosemary, lavender and clary sage oils from manufacture A, and peppermint, sweet marjoram and rosemary oils from manufacture B showed lower MICs with Tween 20 (Tables 3 and 4).

The MICs of rosemary varied significantly under all the test conditions; with Tween 80, Tween 20, and no surfactant. Among the other four Lamiaceae oils, sweet marjoram and clary sage showed significant difference in MIC values when Tween 80 was added (Tables 3 and 4). 
Table 3. The MICs and MFCs of the five Lamiaceae essential oils (Manufacture A) against C. albicans.

\begin{tabular}{|c|c|c|c|c|c|c|}
\hline \multirow{2}{*}{$\begin{array}{l}\text { Aromatic plants } \\
\text { Common name }\end{array}$} & \multicolumn{2}{|c|}{ without surfactant } & \multicolumn{2}{|c|}{ with Tween 80} & \multicolumn{2}{|c|}{ with Tween 20} \\
\hline & MIC & MFC & MIC & MFC & MIC & MFC \\
\hline Rosemary & $10.0-20.0<{ }^{* *}$ & 20.00 & $1.25-5.0^{* *}$ & $2.5-5.0$ & $0.63-2.5^{* *}$ & $1.25-2.5$ \\
\hline Peppermint & $10.0-20.0^{* *}$ & $10.0-20.0$ & $1.25-2.5$ & 2.5 & 1.25 & 1.25 \\
\hline Lavender & 20.0 & 20.0 & $2.5-5.0$ & 5.0 & $1.25-2.5$ & 2.5 \\
\hline Sweet marjoram & $20.0-20.0<$ & 20.0 & $2.5^{* *}$ & 2.5 & 2.5 & 2.5 \\
\hline Clary sage & $20.0-20.0<$ & 20.0 & $10.0-20.0^{* *}$ & $10.0-20.0$ & $5.0-10.0$ & 10.0 \\
\hline
\end{tabular}

The numerical values are indicated in $\mu 1 / \mathrm{ml}$. The addition of Tween 80 or Tween 20 affected MICs significantly. MIC values did not vary significantly between Tween 80 and Tween $20 .{ }^{* *} P<0.05$ vs Manufacture B.

Table 4. The MICs and MFCs of the five Lamiaceae essential oils (Manufacture B) against C. albicans.

\begin{tabular}{|c|c|c|c|c|c|c|}
\hline \multirow{2}{*}{$\begin{array}{l}\text { Aromatic plants } \\
\text { Common name }\end{array}$} & \multicolumn{2}{|c|}{ without surfactant } & \multicolumn{2}{|c|}{ with Tween 80} & \multicolumn{2}{|c|}{ with Tween 20} \\
\hline & MIC & MFC & MIC & MFC & MIC & MFC \\
\hline Peppermint & $20.0<* *$ & $20.0<$ & 1.25 & 1.25 & $0.63-1.25$ & $0.63-1.25$ \\
\hline Lavender & 20.0 & 20.0 & $2.5-5.0$ & $2.5-5.0$ & 2.5 & 2.5 \\
\hline Sweet marjoram & 20.0 & 20.0 & $5.0^{* *}$ & 5.0 & $2.5-5.0$ & $2.5-5.0$ \\
\hline Clary sage & $20.0-20.0<$ & 20.0 & $5.0-10.0^{* *}$ & $5.0-10.0$ & 10.0 & 10.0 \\
\hline Rosemary & $20.0<* *$ & $20.0<$ & $10.0^{* *}$ & 10.00 & $5.0-10.0^{* *}$ & $5.0-10.0$ \\
\hline
\end{tabular}

The numerical values are indicated in $\mu \mathrm{l} / \mathrm{ml}$. The addition of Tween 80 or Tween 20 affected MICs significantly. MIC values did not vary significantly between Tween 80 and Tween $20 .{ }^{* *} \mathrm{P}<0.05$ vs Manufacture A.

Arranged in ascending order according to the MIC values, peppermint comes first, followed by lavender, sweet marjoram and clary sage, with no difference between the manufactures. Peppermint showed the same level of MICs as CINEOL. Rosemary oils from manufactures A and B presented contradicting MIC values. It is on the top in manufacture A and at the bottom in manufacture B (Tables 3 and 4). In some oils, including peppermint, MIC and MFC values coincided when Tween 80 or 20 added (Tables 3 and 4).

\section{Discussion}

The data presented here revealed a correlation between surfactants and decrease in MICs of the essential oils. There was no significant difference observed between the non-ionic surfactants, Tween 80 and Tween 20, but the values tended to be lower when Tween 20 added. Only CAMPHOR showed significant drop in MIC values with Tween 20. The tested four Lamiaceae oils, of which chemotypes are not available, showed no significant variation in MICs by manufacturers. The distinct values from CAMPHOR suggest that the different chemical components in chemotype oils provide their unique properties.

A possible explanation for the increased antifungal activity of the essential oils is that Tween 80 and Tween 20 enhanced emulsification or solubilization of fat soluble components of essential oils in liquid culture medium. Hydrophile-Lipophile Balance (HLB) value, proposed by Griffin, is one of the indexes in selecting non-ionic surfactants [10] [11]. It is defined as a value to indicate the affinity of a surfactant for water and oil. On a scale from 0 to 20, a value closer to 20 indicates higher hydrophilia while a value closer to 0 indicates higher lipophilia. The HLB value can be used to divide non-ionic surfactants into hydrophilic oil-in-water (o/w) type and lipophilic water-in-oil (w/o) type. That HLB value of Tween 80 and Tween 20 is 15.0 and 16.8 respectively [10] indicates Tween 20 being more hydrophilic. The difference in hydrophilicity could have affected the result of our study using broth dilution.

In addition, of all the essential oils tested, only CAMPHOR showed significantly lower MIC with Tween 20 than with Tween80. It is said that all oils, waxes and other materials to be incorporated into emulsion have own 
"Required HLB". As Orafidiya et al. reported, it is important that the surfactant system HLB value matches the required HLB value of oil for the emulsion stability [12]. There is a possibility that the required HLB of CAMPHOR was the closest to the HLB of Tween 20. It can be assumed that this is one of the factors affecting the distinct result from CAMPHOR.

An acyl group (RCO-) of Tween 80 is mainly oleic acid, on the other hand, RCO- in Tween 20 is lauric acid. Bergsson et al. reported that lauric acid decreased the number of viable cells of C. albicans in 30 minutes [13], however, we did not find any significant antiproliferative effect in either of these surfactants (data not shown). The tested essential oils showed lower MICs against $C$. albicans when supplemented with Tween 20 than with Tween 80 . These results suggest it is not chemical structure but solubility of surfactants that affects the activity of essential oils.

The five Lamiaceae essential oils tested in our study showed almost same MIC and MFC values. It is suggested that the essential oils, with or without surfactants, have fungicidal activities. Menthone and menthol are known as main components of peppermint [14] [15]. These two components are reported to act against C. albicans based on a study on their MICs and MFCs using broth microdilution method [16]. Linalool and linalyl acetate are the main components of lavender and clary sage [17]-[19]. According to previous studies by time-kill assay, these components decreased the number of viable cells of C. albicans [20] [21]. Furthermore, linalool was reported to inhibit biofilm formation by C. albicans [22]. Terpinene-4-ol and $\gamma$-terpinene, the main components of sweet marjoram [23], were reported to decrease the number of viable cells of $C$. albicans in a previous study by time-kill assay [24]. All these findings clearly indicate that some of the components in Lamiaceae family oils are active against $C$. albicans, and validate their antifungal activity. The MIC values of the five oils but rosemary did not vary between the two manufactures. Since the chemotypes of the four essential oils (peppermint, lavender, sweet marjoram and clary sage) are not available in Japan, the ratio of major components may not be varied remarkably by species.

In this study, we clarified that surfactant (Tween 80 or Tween 20) plays a critical role in significant decrease of MICs of essential oils against $C$. albicans. Their combined effects suggest that we need to consider the type of surfactant as well as essential oil in investigating its peculiar therapeutic properties. Lamiaceae family peppermint showed MICs as low as rosemary CINEOL. The mechanism of fungicidal action makes peppermint one of the promising substitute for drugs against $C$. albicans.

\section{Conclusion}

In this study, we clarified that surfactant (Tween 80 or Tween 20) plays a critical role in significant decrease of MICs of essential oils against $C$. albicans. Their combined effects suggest that we need to consider the type of surfactant as well as essential oil in investigating its peculiar therapeutic properties. Lamiaceae family peppermint showed MICs as low as rosemary CINEOL. The mechanism of fungicidal action makes peppermint one of the promising substitutes for drugs against C. albicans.

\section{References}

[1] Dorman, H.J.D. and Deans, S.G. (2000) Antimicrobial Agents from Plants: Antibacterial Activity of Plant Volatile Oils. Journal of Applied Microbiology, 88, 308-316. http://dx.doi.org/10.1046/j.1365-2672.2000.00969.x

[2] Burt, S. (2004) Essential Oils: Their Antibacterial Properties and Potential Applications in Foods-A Review. International Journal of Food Microbiology, 94, 223-253.

[3] Hyldgaard, M., Mygind, T. and Meyer, R.L. (2012) Essential Oils in Food Preservation: Mode of Action, Synergies, and Interactions with Food Matrix Components. Frontiers in Microbiology, 3, 1-24. http://www.frontiersin.org/Antimicrobials\%2c_Resistance_and_Chemotherapy/10.3389/fmicb.2012.00012/abstract

[4] Matsuzaki, Y., Tsujisawa, T., Nishihara, T., Nakamura, M. and Kakinoki, Y. (2013) Antifungal Activity of Chemotype Essential Oils from Rosemary against Candida albicans. Open Journal of Stomatology, 3, 176-182. http://file.scirp.org/Html/9-1460236_32053.htm

[5] Fu, Y., Zu, Y., Chen, L., Shi, X., Wang, Z., Sun, S. and Efferth, T. (2007) Antimicrobial Activity of Clove and Rosemary Essential Oils Alone and in Combination. Phytotherapy Research, 21, 989-994. http://dx.doi.org/10.1002/ptr.2179

[6] Rasooli, I., Fakoor, M.H., Yadegarinia, D., Gachkar, L., Allameh, A. and Rezaei, M.B. (2008) Antimycotoxigenic Characteristics of Rosmarinus officinalis and Trachyspermum copticum L. Essential Oils. International Journal of Food 
Microbiology, 122, 135-139. http://www.sciencedirect.com/science/article/pii/S0168160507006356 http://dx.doi.org/10.1016/j.ijfoodmicro.2007.11.048

[7] Jiang, Y., Wu, N., Fu, Y.J., Wang, W., Luo, M., Zhao, C.J., Zu, Y.G. and Liu, X.L. (2011) Chemical Composition and Antimicrobial Activity of the Essential Oil of Rosemary. Environmental Toxicology and Pharmacology, 32, 63-68. http://www.sciencedirect.com/science/article/pii/S1382668911000469 http://dx.doi.org/10.1016/j.etap.2011.03.011

[8] Kerwin, B.A. (2008) Polysorbates 20 and 80 Used in the Formulation of Protein Biotherapeutics: Structure and Degradation Pathways. Journal of Pharmaceutical Sciences, 97, 2924-2935.

http://onlinelibrary.wiley.com/doi/10.1002/jps.21190/abstract;jsessionid=AFF72AF4035BBBB28E9C31589833069F.f 01t01 http://dx.doi.org/10.1002/jps.21190

[9] Deechongkit, S., Wen, J., Narhi, L.O., Jiang, Y., Park, S.S., Kim, J. and Kerwin, B.A. (2009) Physical and Biophysical Effects of Polysorbate 20 and 80 on Darbepoetin Alfa. Journal of Pharmaceutical Sciences, 98, 3200-3217. http://onlinelibrary.wiley.com/doi/10.1002/jps.21740/abstract http://dx.doi.org/10.1002/jps.21740

[10] Griffin, W.C. (1949) Classification of Surface-Active Agents by “HLB”. Journal of Cosmetic Science, 1, 311-326. http://journal.scconline.org/contents/cc1949/cc001n05.html

[11] Pasqualia, R.C., Bregnia, C. and Taurozzia, M.P. (2009) New Values of the Required Hydrophilic-Lipophilic Balance for Oil in Water Emulsions of Solid Fatty Acids and Alcohols Obtained from Solubility Parameter and Dielectric Constant Values. Journal of Dispersion Science and Technology, 30, 328-331. http://www.tandfonline.com/doi/abs/10.1080/01932690802540517\#.UtzDBtKAaM8 http://dx.doi.org/10.1080/01932690802540517

[12] Orafidiya, L.O. and Oladimeji, F.A. (2002) Determination of the Required HLB Values of Some Essential Oils. International Journal of Pharmaceutics, 237, 241-249.

http://www.sciencedirect.com/science/article/pii/S0378517302000510 http://dx.doi.org/10.1016/S0378-5173(02)00051-0

[13] Bergsson, G., Arnfinnsson, J., Steingrímsson, Ó. and Thormar, H. (2001) In Vitro Killing of Candida albicans by Fatty Acids and Monoglycerides. Antimicrobial Agents and Chemotherapy, 45, 3209-3212. http://aac.asm.org/content/45/11/3209.long http://dx.doi.org/10.1128/AAC.45.11.3209-3212.2001

[14] Inouye, S., Takizawa, T. and Yamaguchi, H. (2001) Antibacterial Activity of Essential Oils and Their Major Constituents against Respiratory Tract Pathogens by Gaseous Contact. The Journal of Antimicrobial Chemotherapy, 47, 565-573. http://jac.oxfordjournals.org/content/47/5/565.long http://dx.doi.org/10.1093/jac/47.5.565

[15] Edris, A.E. and Farrag, E.S. (2003) Antifungal Activity of Peppermint and Sweet Basil Essential Oils and Their Major Aroma Constituents on Some Plant Pathogenic fungi from the Vapor Phase. Die Nahrung, 47, 117-121. http://dx.doi.org/10.1002/food.200390021

[16] Marcos-Arias, C., Eraso, E., Madariaga, L. and Quindós, G. (2011) In Vitro Activities of Natural Products against Oral Candida Isolates from Denture Wearers. BMC Complementary and Alternative Medicine, 11, 1-7. http://www.ncbi.nlm.nih.gov/pmc/articles/PMC3258290/

[17] Shellie, R., Mondello, L., Marriott, P. and Dugo, G. (2002) Characterisation of Lavender Essential Oils by Using Gas Chromatography-Mass Spectrometry with Correlation of Linear Retention Indices and Comparison with Comprehensive Two-Dimensional Gas Chromatography. Journal of Chromatography A, 970, 225-234. http://dx.doi.org/10.1016/S0021-9673(02)00653-2

[18] Prashar, A., Locke, I.C. and Evans, C.S. (2004) Cytotoxicity of Lavender Oil and Its Major Components to Human Skin Cells. Cell Proliferation, 37, 221-229. http://onlinelibrary.wiley.com/doi/10.1111/j.1365-2184.2004.00307.x/abstract http://dx.doi.org/10.1111/j.1365-2184.2004.00307.x

[19] Džamić, A., Soković, M., Ristić, M., Grujić-Jovanović, S., Vukojević, J. and Marin, P.D. (2008) Chemical Composition and Antifungal Activity of Salvia sclarea (Lamiaceae) Essential Oil. Archives of Biological Sciences, 60, 233-237. http://www.doiserbia.nb.rs/img/doi/0354-4664/2008/0354-46640802233D.pdf http://dx.doi.org/10.2298/ABS0802233D

[20] D’Auria, F.D., Tecca, M., Strippoli, V., Salvatore, G., Battinelli, L. and Mazzanti, G. (2005) Antifungal Activity of Lavandula angustifolia Essential Oil against Candida albicans Yeast and Mycelial Form. Medical Mycology, 43, 391396. http://dx.doi.org/10.1080/13693780400004810

[21] Zore, G.B., Thakre, A.D., Jadhav, S. and Karuppayil, S.M. (2011) Terpenoids Inhibit Candida albicans Growth by Affecting Membrane Integrity and Arrest of Cell Cycle. Phytomedicine, 18, 1181-1190. http://www.sciencedirect.com/science/article/pii/S0944711311001206 http://dx.doi.org/10.1016/j.phymed.2011.03.008

[22] Hsu, C.C., Lai, W.L., Chuang, K.C., Lee, M.H. and Tsai, Y.C. (2013) The Inhibitory Activity of Linalool against the Filamentous Growth and Biofilm Formation in Candida albicans. Medical Mycology, 51, 473-482. 
http://informahealthcare.com/doi/abs/10.3109/13693786.2012.743051 http://dx.doi.org/10.3109/13693786.2012.743051

[23] Novak, J., Langbehn, J., Pank, F. and Franz, C.M. (2002) Essential Oil Compounds in a Historical Sample of Marjoram (Origanum majorana L., Lamiaceae). Flavour and Fragrance Journal, 17, 175-180.

http://onlinelibrary.wiley.com/doi/10.1002/ffj.1077/abstract http://dx.doi.org/10.1002/ffj.1077

[24] Hammer, K.A., Carson, C.F. and Riley, T.V. (2003) Antifungal Activity of the Components of Melaleuca alternifolia (Tea Tree) Oil. Journal of Applied Microbiology, 95, 853-860. http://onlinelibrary.wiley.com/doi/10.1046/j.1365-2672.2003.02059.x/abstract http://dx.doi.org/10.1046/j.1365-2672.2003.02059.x 